\title{
The role of heat treatment in light oxidation of fluid milk
}

\author{
W. S. Harwood, B. G. Carter, D. C. Cadwallader, and M. A. Drake* (1) \\ Department of Food, Bioprocessing, and Nutrition Sciences, Southeast Dairy Foods Research Center, North Carolina State University, \\ Raleigh 27695
}

\begin{abstract}
Light-oxidized flavor (LOF) resulting from photooxidation of riboflavin following light exposure is one of the most common off-flavors in fluid milk. The sensory perception of LOF has been studied extensively in high temperature, short time pasteurized (HTST) milk, but few studies have evaluated ultrapasteurized (UP) milk. The objective of this study was to evaluate the role of heat treatment in the development of LOF in UP fluid skim milk. Skim milk was processed by HTST or by direct steam injection (DSI-UP) and subsequently exposed to 2,000-lx light-emitting diode light for various times. Sensory properties were monitored by descriptive analysis and threshold tests, and volatile compounds were evaluated by solid phase microextraction with gas chromatography-mass spectrometry. Dissolved oxygen and riboflavin were determined at each time point using an oxygen meter and ultra-performance liquid chromatography with a fluorescence detector, respectively. The entire experiment was performed in triplicate. Typical cardboard and mushroom flavors (LOF) were detected by trained panelists in HTST milk after $3.5 \mathrm{~h}$ of light exposure. In contrast, LOF was not detected by trained panelists in UP milk until $36 \mathrm{~h}$ of light exposure. Similarly, the best estimate threshold for LOF from untrained consumers $(\mathrm{n}=101)$ was higher for DSI-UP milk $(61.0 \mathrm{~h})$ than for HTST milk $(15.2 \mathrm{~h})$. Milks with LOF were characterized by higher relative abundance of the lipid oxidation compounds hexanal and heptanal. Dissolved oxygen (DO) and riboflavin concentrations decreased with increased light exposure time, and the decrease was slower in UP milk compared with HTST milk. Initial DO concentration was investigated as a possible influence in LOF development because DSI-UP milks had lower initial DO concentrations than HTST milks. However, follow-up evaluations of deaerated HTST milks suggested that DO was not
\end{abstract}

Received May 21, 2020.

Accepted July 20, 2020.

*Corresponding author: mdrake@ncsu.edu a significant factor in LOF development. These results demonstrate that UP milk is less sensitive to LOF than HTST milk, possibly due to sensory masking effects or antioxidant effects of volatile sulfur compounds. An enhanced understanding of light and storage effects on milks will assist with best practices when transporting and displaying fluid milk products for sale.

Key words: milk, oxidation, pasteurization, threshold

\section{INTRODUCTION}

Thermal processing of fluid milk is central to fluid milk quality. Under typical HTST pasteurization conditions (minimum of $72^{\circ} \mathrm{C}$ for $15 \mathrm{~s}$ ), fluid milk has a shelf life of approximately $3 \mathrm{wk}$, after which milk quality deteriorates due to microbial load. Shelf life of fluid milk may be significantly extended through the application of elevated thermal processing. Ultrapasteurization (UP) of fluid milk (minimum of $138^{\circ} \mathrm{C}$ for at least $2 \mathrm{~s}$ ), for example, results in a shelf life of about $60 \mathrm{~d}$ (Boor and Nakimbugwe, 1998). Ultrapasteurized fluid milk is advantageous to fluid milk producers and retailers because the extended shelf life of such products reduces risk of product loss and helps assuage supply chain demands. However, elevated pasteurization temperatures have been shown to impart increased cooked and sulfur flavors, which result in decreased consumer liking (Chapman and Boor, 2001; Gandy et al., 2008). Lee et al. (2017) showed that milk consumers, both adults and children, maintained preference for HTST milk over UP milk regardless of fat content. Additionally, Lee et al. (2017) demonstrated that the cooked and sulfur or eggy flavors imparted by UP treatment of fluid milk decreased over shelf life but were still distinct through $14 \mathrm{~d}$ postprocessing.

Although extended shelf life is an attractive feature to fluid milk processors and retailers, longer time in a retail setting increases the likelihood of extended light exposure. The development of off-flavors in milk due to photooxidation of riboflavin and other photosensitive compounds in milk has been widely linked to increased concentrations of volatile aldehydes such as methional, hexanal, heptanal, and octanal and a corresponding 
decrease in consumer acceptance (Johnson et al., 2015; Brothersen et al., 2016). Aldehyde formation in fluid milk is primarily caused by light-induced degradation of methionine and oxidation of unsaturated fatty acids (Marsili, 1999; Min and Boff, 2002). Accumulation of volatile aldehydes and other oxidation-related compounds results in off-flavor development, commonly referred to as light-activated flavor or light-oxidized flavor (LOF). In skim fluid milk and other dairy products, LOF is commonly described as "burnt," "tallow," "cardboard," "mushroom," or "cabbage-like," although several other descriptors have been used (Bodyfelt et al., 1988; Brothersen et al., 2016).

Mitigation of light oxidation has been most commonly addressed through the use of light-blocking packaging materials. Traditionally, UP milk has been packaged in gable-top polyethylene-coated paperboard containers, which provides extensive yet imperfect protection from light (Rysstad et al., 1998). Single-serve containers and larger volume polyethylene packages have also emerged for UP milk products. Paperboard cartons provide strong light protection, but the majority of fluid milk consumers have reported a preference for packaging materials that allow for product visibility, such as glass, high-density polyethylene, or polyethylene terephthalate (Wang et al., 2018). Mestdagh et al. (2005) showed that high-density polyethylene bottles with either an added oxygen-binding inner layer or UV light filter failed to stop light oxidation in UP milk; however, the addition of a UV-absorbing material offered slight protection. Use of $\mathrm{TiO}_{2}$ pigments or secondary light-blocking materials, such as foil wraps, were shown to be successful in mitigating light oxidation in reduced-fat UP milk (Stancik et al., 2017). However, these applications may present significant cost barriers (compared with standard high-density polyethylene containers) and may be negatively perceived by consumers in shopping situations due to decreased product visibility (Webster et al., 2009; Wang et al., 2018).

In addition, the efficacy of antioxidant addition on the prevention of light oxidation in fluid milk has been investigated. Experiments by van Aardt et al. (2005) reported that addition of $\alpha$-tocopherol decreased hexanal formation during storage, whereas additions of butylated hydroxyanisole and butylated hydroxytoluene decreased pentanal, hexanal, heptanal, and 1-octen-3-ol, although consumer-relevant intensities of LOF were not assessed. The addition of vitamin premixes was found to have no effect on LOF development in HTST skim milk (Schiano et al., 2019). Flavor and sweetener addition, although not directly oriented at the mitigation of oxidation, has also proven effective in protecting fluid milk from the negative sensory effects of LOF develop- ment. Chapman et al. (1998) determined that the addition of cocoa and carrageenan to fluid milk successfully inhibited vitamin A degradation but was ultimately ineffective in preventing LOF development. Although flavor addition failed to prevent LOF, threshold studies by van Aardt et al. (2001) showed that consumers of whole (3.25\% milkfat) chocolate milk had a significantly higher threshold for light-induced off-flavor than for unflavored fluid milks of various fat levels. Similar findings were also reported in fluid milks formulated with sucrose and strawberry flavor (Bills et al., 1972). Results from these studies indicate that flavored milk formulations may not directly address LOF development, but flavoring can serve as a means for masking off-flavors and preserving consumer acceptance.

Intrinsic qualities of fluid milk such as milkfat content also influence oxidative stability and development of LOF. In terms of milkfat, Whited et al. (2002) showed that under 2,000-lx fluorescent light, skim milk had greater vitamin and riboflavin loss than reducedfat or whole milk and LOF developed more rapidly at early time points ( $2 \mathrm{~h}$ of light exposure); however, LOF intensity was greater in reduced-fat and whole milk samples compared with skim milk after extended light exposure ( $4 \mathrm{~h}$ or more). Although greater milkfat content may result in higher intensities of LOF, consumer evaluations indicate that overall liking of $2 \%$ milk was penalized less than skim milk following light exposure, in agreement with general consumer preference for milk with higher fat content (Martin et al., 2016; McCarthy et al., 2017). Skim milk, as such, remains the most flavor-transparent matrix for evaluation of LOF in milk.

Overall, there has been limited investigation into the roles different processing parameters play on the development of light oxidation in fluid milk. The existing literature primarily addresses the phenomenon indirectly through evaluation of riboflavin degradation. Saidi and Warthesen (1995) reported that heat treatment $\left(80,100\right.$, and $\left.120^{\circ} \mathrm{C}\right)$ and homogenization (single stage: $35 \mathrm{~kg} \mathrm{~cm}^{-2}$; double stage: $175 \mathrm{~kg} \mathrm{~cm} \mathrm{~cm}^{-2}$ and 35 $\mathrm{kg} \mathrm{cm}{ }^{-2}$ ) of skim milk resulted in decreased rates of riboflavin degradation, although this improvement was primarily attributed to greater light scattering following homogenization.

The objectives of this study were to investigate the relationship between thermal processing and development of LOF in skim milk using both analytical measurements (descriptive analysis, volatile flavor analysis, riboflavin measurement) and consumer-relevant methodologies (threshold testing). A holistic understanding of these processes may help guide best practices related to processing, storage, and display of commercial fluid milks to ensure ideal product quality. 


\section{MATERIALS AND METHODS}

\section{Milk Processing and Light Exposure}

Raw skim milk (200 L per lot; $0.083 \pm 0.001 \%$ fat) for this study was obtained from the North Carolina State University Dairy Enterprise System (Raleigh, NC). Somatic cell count (SomaScope, Delta Instruments B.V., Drachten, the Netherlands) of the raw milk was $<100,000$ cells $/ \mathrm{mL}$ for each lot of milk, and the coliform count of each lot was $<10 \mathrm{cfu} / \mathrm{mL}$. Each lot of skim milk was divided into 2 portions $(100 \mathrm{~L}$ each), and HTST pasteurization or direct steam injection (DSI)-UP were conducted using a MicroThermics EHVH pasteurization unit (MicroThermics, Raleigh, NC) with a 2-stage homogenizer (GEA Niro Soavi, Parma, Italy) as described by Lee et al. (2017; Figure 1). Microbial counts and alkaline phosphatase tests were conducted postpasteurization to ensure pasteurization and appropriate microbial quality as described by Lee et al. (2017). Following thermal processing and cooling to $10^{\circ} \mathrm{C}$, milks were bottled in translucent, half-gallon, high-density polyethylene milk jugs (Upstate Niagara Cooperative Inc., Buffalo, NY) under an Aseptilab ultra-clean fill hood (MicroThermics). Milk containers were placed in a walk-in cooler and stored in the dark at $4^{\circ} \mathrm{C}$ for $48 \mathrm{~h}$ to simulate postprocess transit time, similar to commercial products. These processes were repeated in triplicate.

Following $48 \mathrm{~h}$ at $4^{\circ} \mathrm{C}$, milks were placed into 1 of 2 light boxes $(88 \times 57 \times 31 \mathrm{~cm})$ constructed as described by Schiano et al. (2019). Light boxes were covered with laser cloth (BK5 blackout fabric, ThorLabs Inc., Newton, NJ) to eliminate ambient light from reaching samples during exposure. Within each light box, light-emitting diode strips $(3500 \mathrm{~K}$, International Light Technologies, Peabody, MA) were affixed to the roof to supply a light intensity of 2,000 lx $( \pm 20 \mathrm{~lx})$ throughout the box at the height of the milk jugs. Light boxes were located within a walk-in cooler at $4^{\circ} \mathrm{C}$.

Experimental exposure times for HTST and DSI-UP milks were determined following a preliminary tasting trial with untrained assessors $(\mathrm{n}=16)$ from the general North Carolina State University student population. Milks from each treatment were exposed to light at 4-h increments for up to $48 \mathrm{~h}$. Trial participants were asked to indicate at what point they believed a noticeable difference was imparted to the milk samples by first tasting an unexposed control sample and then tasting the exposed milks in order of exposure time. Participants were presented with treatments in a balanced design to mitigate order effects. Following these trials, suggested midpoints of 8 and $36 \mathrm{~h}$ were chosen for HTST and DSI-UP milks, respectively. A $1.5 \times$ step factor was subsequently applied to the midpoint of each treatment, resulting in the following experimental time points for the study: HTST samples were removed from the light boxes at $2.43 .6,5.3,8,12,18$, and $27 \mathrm{~h}$, and DSI-UP milk samples were removed at 10.67, 16, 24, 36, 54, 81, and $121.5 \mathrm{~h}$. Once removed, milks were placed in a light-shield box covered with laser cloth to ensure no further light exposure was introduced. Unexposed control milks for each pasteurization method were also prepared and placed directly into a light-shielded box postprocessing. At the conclusion of the 121.5-h maximum exposure time, all milks were subjected to descriptive sensory analysis, sensory threshold testing, and instrumental analyses. The entire experimental design was replicated in triplicate.

\section{Riboflavin and Dissolved Oxygen Measurement}

Riboflavin content and degradation over the course of light exposure were determined in accordance with the procedure developed by Silva et al. (2005). Sample preparation consisted of protein precipitation using trichloroacetic acid, centrifugation, and filtration of the supernatant through a $0.2-\mu \mathrm{m}$ nylon filter. Riboflavin concentration was measured by ultra-performance liquid chromatography (Acquity H-Class; Waters Corporation, Milford, MA) with fluorescence detection

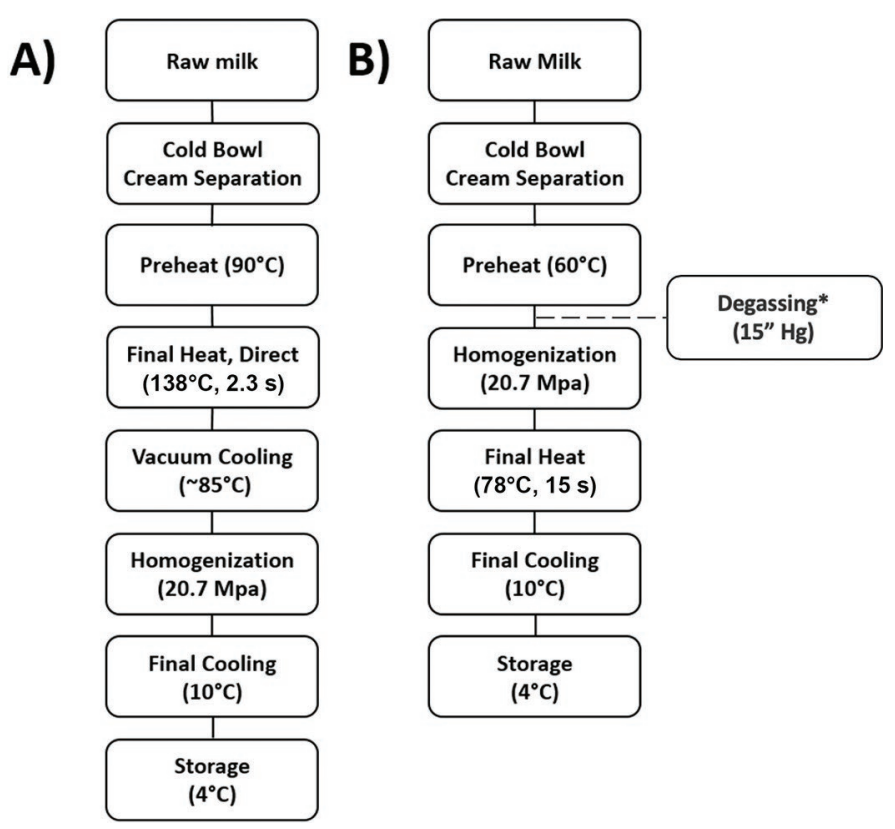

Figure 1. Process flow diagram for (A) direct steam injection ultrapasteurization (DSI-UP) and (B) HTST skim milk treatments. Asterisk indicates that degassing of HTST-processed milks was conducted only for HTST versus degassed HTST treatment comparisons, not as a part of HTST versus DSI-UP treatment comparisons. 
$($ excitation $=420 \mathrm{~nm}$, emission $=530 \mathrm{~nm})$. The concentration of riboflavin $(\mu \mathrm{g} / \mathrm{mL})$ was calculated using a relative response factor determined with calibration standards $(0.1-0.3 \mu \mathrm{g} / \mathrm{mL}$; Sigma-Aldrich, St. Louis, MO). Dissolved oxygen (DO) was measured using a YSI-5100 dissolved oxygen meter with a self-stirring probe (YSI Inc., Yellow Springs, OH). The instrument was calibrated before each use using a biochemical oxygen demand bottle containing 1 inch of water in accordance with the device manual. Milk aliquots (400 $\mathrm{mL}, 10^{\circ} \mathrm{C}$ at time of measurement) from 2 bottles of each thermal process-light exposure treatment were prepared and measured for each replication of the experiment by submerging the self-stirring probe in the milk aliquot.

\section{Trained Panel Profiling}

Sensory analysis of milks was conducted to understand the relevant sensory changes brought about from light exposure. Sensory profiling of milks was approved by the North Carolina State University Institutional Review Board for Human Subjects. A trained panel of 8 descriptive analysis panelists ( 2 men, 6 women; ages $21-55 \mathrm{yr}$ ), each with at least $150 \mathrm{~h}$ of prior experience profiling fluid milk and dairy products, profiled intensities of typical milk flavor attributes (Jo et al., 2018) and light oxidation-specific flavors such as cardboard and mushroom (Schiano et al., 2019) using the spectrum method 15-point intensity scale (Meilgaard et al., 2007; Table 1). Aliquots (40 mL) of milk from each treatment were dispensed into $65-\mathrm{mL}$ soufflé cups labeled with random 3-digit blinding codes and were subsequently lidded and equilibrated to $15^{\circ} \mathrm{C}$. Trained panel profiling was conducted in a room with overhead lights turned off to ensure no further light exposure was introduced to the samples. Data from each panelist were collected on an iPad (Apple, Cupertino, CA) interface with Compusense Cloud (Guelph, ON, Canada) software. Each milk from each experimental replicate was evaluated in duplicate by each panelist according to a replicated balanced complete block design (16 total samples tasted per session). Panelists were instructed to expectorate samples after tasting and cleanse their palates during a 2-min enforced rest between samples using provided unsalted crackers and deionized water.

Table 1. Descriptive sensory profiles of control and light-exposed HTST and direct steam injection ultrapasteurization (DSI-UP) skim milks following light exposure ${ }^{1}$

\begin{tabular}{|c|c|c|c|c|c|}
\hline $\begin{array}{l}\text { Light exposure } \\
\text { duration }(\mathrm{h})\end{array}$ & $\begin{array}{c}\text { Sweet } \\
\text { aromatic }\end{array}$ & Cooked/milky & Cardboard & Mushroom & Eggy/sulfur \\
\hline \multicolumn{6}{|l|}{ HTST } \\
\hline 0 (control) & 2.3 & 3.2 & $\mathrm{ND}^{2}$ & ND & ND \\
\hline 2.4 & 1.8 & 3.0 & 0.7 & ND & ND \\
\hline 3.6 & 1.3 & 3.0 & 1.6 & 0.7 & ND \\
\hline 5.3 & 0.8 & 3.0 & 2.2 & 1.3 & ND \\
\hline 8 & 0.8 & 3.0 & 2.3 & 1.3 & ND \\
\hline 12 & 0.5 & 2.9 & 2.7 & 1.9 & ND \\
\hline 18 & 0.6 & 2.9 & 2.8 & 2.0 & ND \\
\hline 27 & ND & 2.8 & 3.3 & 2.2 & ND \\
\hline $\mathrm{LSD}^{3}$ & 0.6 & 0.2 & 0.8 & 0.8 & ND \\
\hline \multicolumn{6}{|l|}{ DSI-UP ${ }^{4}$} \\
\hline 0 (control) & 1.3 & 4.0 & ND & ND & 1.9 \\
\hline 10.7 & 1.3 & 4.0 & ND & ND & 1.9 \\
\hline 16 & 1.3 & 3.9 & ND & ND & 1.7 \\
\hline 24 & 1.3 & 3.9 & ND & ND & 1.5 \\
\hline 36 & 1.0 & 3.7 & 0.8 & ND & 0.7 \\
\hline 54 & 1.0 & 3.7 & 0.7 & ND & 0.7 \\
\hline 81 & ND & 3.5 & 1.6 & ND & ND \\
\hline 121.5 & ND & 3.4 & 1.8 & 1.1 & ND \\
\hline $\mathrm{LSD}^{3}$ & 0.7 & 0.3 & 0.5 & $\mathrm{NA}^{5}$ & 0.7 \\
\hline
\end{tabular}

${ }^{1}$ Intensities were scored on a 0 - to 15 -point intensity scale consistent with the spectrum descriptive analysis method (Meilgaard et al., 2007). Most fluid milk flavors fall between 0 and 4 on this scale (McCarthy et al., 2017). Not shown: sweet taste and astringency were also evaluated by the trained sensory panel; however, no differences $(P>0.05)$ with light exposure were noted.

${ }^{2} \mathrm{ND}=$ not detected.

${ }^{3}$ Fisher's LSD $(\alpha=0.05)$.

${ }^{4}$ Direct steam injection ultrapasteurization.

${ }^{5} \mathrm{NA}=$ not applicable. 


\section{Degassing of HTST Milks}

Following collection of data for light-exposed HTST and DSI-UP skim milks from analyses described above, a follow-up investigation of the role of DO was performed to assess whether initial DO concentration was a significant determinant of LOF development. The HTST milk was processed as previously described using a MicroThermics EHVH pasteurization unit (MicroThermics) with a 2-stage homogenizer (GEA Niro Soavi) and was subsequently bottled in translucent, half-gallon, high-density polyethylene milk jugs (Upstate Niagara Cooperative Inc.) under an Aseptilab ultra-clean fill hood (MicroThermics). Additionally, a second lot of HTST milk was prepared following the same processes but was degassed using a vacuum chamber at $380 \mathrm{~mm} \mathrm{Hg}$ following the preheat step. The HTST milks, both degassed (HTST-DG) and not (control), were stored for $48 \mathrm{~h}$ at $4^{\circ} \mathrm{C}$ and then subjected to light exposure as previously described for HTST milks. Milks were evaluated by a trained panel and measured for DO and riboflavin at each experimental time point as previously described. This process was repeated in triplicate.

\section{Volatile Flavor Analysis}

General volatiles from the milks were extracted via headspace solid phase microextraction. Milk $(5 \mathrm{~mL})$ was added to $20-\mathrm{mL}$ amber vials, in triplicate, for each light exposure treatment. Next, $20 \mu \mathrm{L}$ of internal standard (deuterated hexanal in methanol, $507 \mathrm{mg} / \mathrm{kg}$; SigmaAldrich) was added to each vial. Samples were placed on a CTC Analytics CombiPal Autosampler (Zwingen, Switzerland) and were subsequently analyzed on an Agilent 7820 gas chromatograph coupled with a 5975 mass spectrometer (Agilent, Santa Clara, CA) with a ZB-5ms column $(30 \mathrm{~m}$ length $\times 0.25 \mathrm{~mm}$ inner diameter $\times 0.25 \mu \mathrm{m}$ film thickness; Phenomenex, Torrance, CA). Initial analysis was conducted with a standard method scanning from 35 to $340 \mathrm{~m} / z$ to identify compounds of interest. Selected compounds were quantified using relative abundance in SIM mode.

Select sulfur compounds were also evaluated for each milk. Milk $(5 \mathrm{~mL})$ was added to $20-\mathrm{mL}$ amber vials, and $40 \mu \mathrm{L}$ of internal standard (ethyl methyl sulfide in methanol at $1.65 \mathrm{mg} / \mathrm{kg}$; Sigma-Aldrich) was added to each vial. Volatiles were collected via solid phase microextraction and subsequently analyzed using an Agilent 7890B gas chromatograph coupled with an Agilent $7000 \mathrm{C}$ triple quadrupole mass spectrometer equipped with an Agilent sulfur selective flame photo- metric detector with a ZB-5ms column. Sample introduction was conducted via a CTC Analytics CombiPal Autosampler as previously described (Jo et al., 2018). Analytical and operating conditions, including multiple reaction monitoring transition of sulfur compounds and quantification of relative abundances, were conducted as described by Jo et al. (2018).

\section{Threshold Testing}

Determination of the best estimate sensory threshold (BET) for LOF among the general population of fluid milk consumers was determined using a 7-series ascending forced-choice methodology where the stimulus sample corresponded with light-exposed samples of increasing exposure time $(1.5 \times$ step factor $)$ and the other 2 samples were nonexposed controls from the same process run (ASTM, 2019). For each replicate of the experiment, 40 consumers were recruited from a database of more than 10,000 consumers maintained by the North Carolina State University Sensory Service Center. To participate, panelists were required to report that they were regular consumers of fluid milk and that they were regular purchasers or consumers of skim milk. Upon arrival, participants evaluated 2 sets (HTST and DSI-UP milk sets) of 7-series ascending triangle tests (threshold tests). Approximately 20-mL aliquots of milk were served in lidded $60-\mathrm{mL}$ soufflé cups coded with random 3-digit blinding codes. Each series of each test was presented in a randomized order, balanced for signal position across all panelists. Tests (HTST or DSI-UP) were presented in a balanced randomized order for each panelist, and a 5-min enforced rest time was used between tests. Panelists were instructed to taste samples from left to right and pick the "odd" sample out of each row of samples by circling the corresponding blinding code on a paper ballot. A 30-s rest was then enforced after each series, and panelists were instructed to cleanse their palates with provided unsalted crackers and deionized water before continuing to the next series. Threshold testing was conducted on milks at approximately $4^{\circ} \mathrm{C}$.

\section{Data Analysis}

An ANOVA with Fisher's LSD post hoc test for means separation was applied to data from the trained sensory and volatile compound analysis relative abundances to understand differences among the light exposure treatments. Linear regression was applied to DO, and riboflavin degradation data and visualizations were constructed using the ggplot2 package in $\mathrm{R}$ (version 
3.6.2; Wickham, 2016). All statistical analyses were conducted at $95 \%$ confidence using XLSTAT software (Addinsoft, Paris, France).

The BET for LOF was determined for HTST and DSI-UP milks using the methods described by the American Society for Testing and Materials procedure E679-19 (ASTM, 2019). First, individual thresholds were determined by calculating the geometric mean of the highest concentration missed and the next concentration. In the case of a participant correctly identifying the odd sample for all rows or incorrectly identifying the odd sample in the highest concentration row, the hypothetical next concentration above or below according to the $1.5 \times$ step factor was used to calculate the geometric mean for that individual. The group BET for LOF in both HTST and DSI-UP treatments was subsequently calculated by taking the geometric mean of all individual BET for each test. Additionally, the standard deviation was calculated for each treatment from the $\log _{10}$ individual BET to better understand variability in signal detection for LOF among untrained fluid milk consumers.

\section{RESULTS AND DISCUSSION}

\section{Analysis of Riboflavin and DO}

Photosensitized riboflavin in the presence of oxygen is well recognized as the source of singlet oxygen oxidation of lipids and amino acids in fluid milk (Min and Boff, 2002). As such, measurement of riboflavin degradation and DO concentration is indicative of oxidation rate. Changes in riboflavin and DO concentrations over the course of experimental light exposure times for HTST and DSI-UP milks are depicted in Figures 2 and 3, respectively. Rate of riboflavin degradation was significantly greater $(P<0.05)$ in HTST milk than in DSI-UP milk. Likewise, the rate of decrease for DO was greater $(P<0.05)$ in HTST milk than in DSI-UP milk. Based on these findings, HTST milk appears to be more susceptible to light oxidation processes than DSI-UP milk. Initial concentrations of DO were also significantly greater in HTST milks, suggesting that rate of riboflavin degradation and DO decrease may be a function of initial DO concentration.

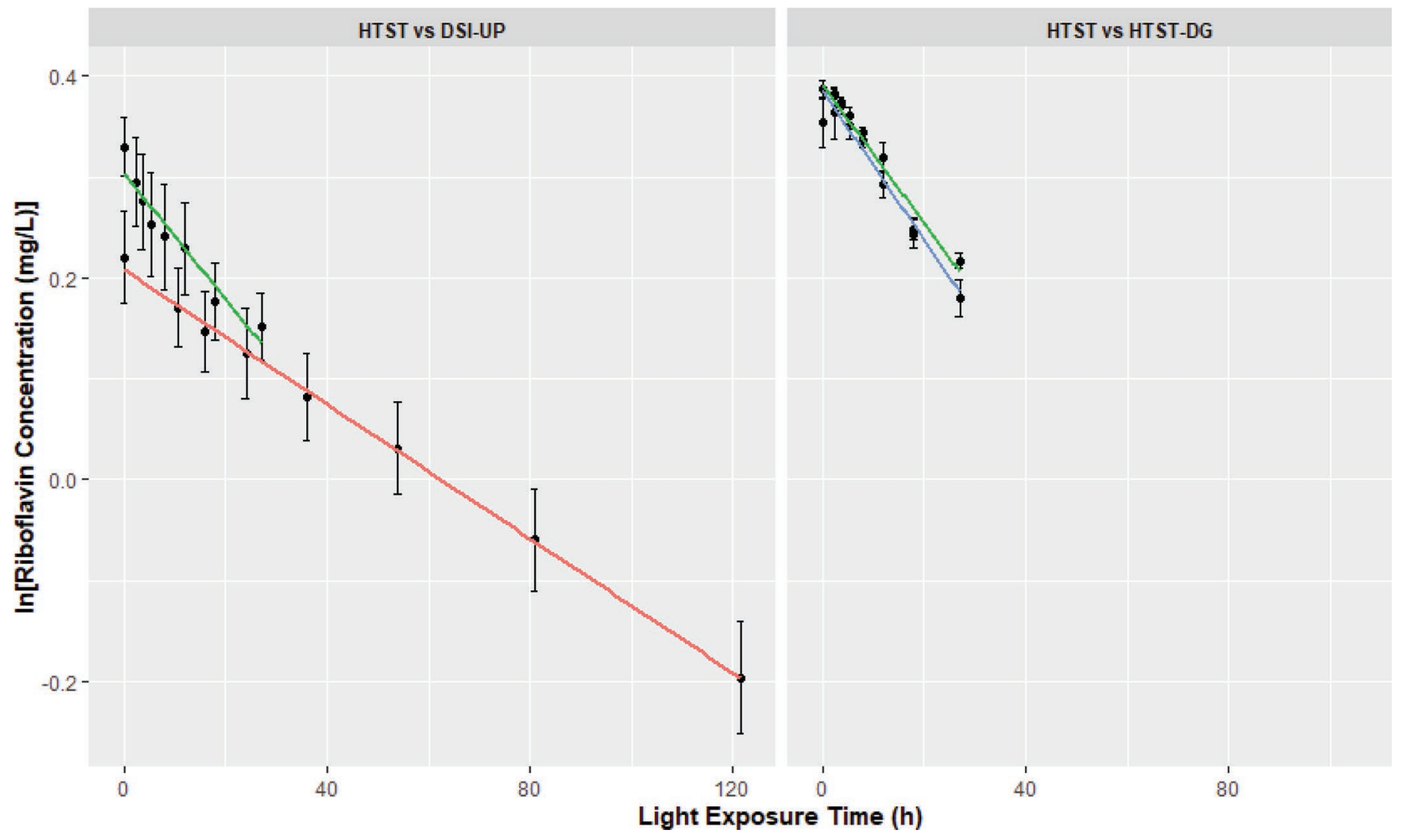

Figure 2. Riboflavin degradation over light exposure time for HTST versus direct steam injection ultrapasteurization (DSI-UP) and HTST versus degassed HTST (HTST-DG) skim milk treatments. Data points represent mean riboflavin concentration measurements, and bars represent the SEM over 3 replicates at each experimental light exposure duration for each treatment. 


\section{Trained Panel Sensory Profiling}

Trained panel profiling of light-exposed milks was conducted at each experimental time point (Table 1). For HTST milk, the unexposed control was characterized by moderate intensities of sweet aromatic (mean $=$ 2.3 ) and cooked (mean $=3.2$ ) flavors and was devoid of cardboard or mushroom flavors (no LOF). The LOF development in HTST skim milk was characterized by a decrease $(P<0.05$; compared with unexposed control) in sweet aromatic flavor (mean $=1.3)$ and an increase in cardboard flavor (mean $=1.6$ ) signal by $3.5 \mathrm{~h}$, although a threshold signal for cardboard flavor was also noted by the trained panel at $2.4 \mathrm{~h}$. Significant $(P<$ $0.05)$ development of mushroom flavor was noted by 5.3 $\mathrm{h}($ mean $=1.3)$. Observations by Whited et al. (2002) similarly observed noticeable flavor differences in skim and reduced-fat milks after about $2 \mathrm{~h}$ of 2,000-lx light exposure, which increased linearly in intensity with increased exposure time. In the present study, the onset of LOF in HTST milk was characterized by decreased sweet aromatic flavor intensity and the development of cardboard and mushroom flavors. Following these time points, mushroom and cardboard flavor intensities continued to increase in intensity. Linear increases of LOF in fluid milk have also been reported by Chapman et al. (2002), although evaluations of light-exposed $1 \%$ milk by Brothersen et al. (2016) suggested that the presence of butterscotch flavor (an LOF attribute in fat-containing milks) may not follow a linear pattern. Over the $27 \mathrm{~h}$ of total light exposure time used for HTST milk in the present study, no significant changes in cooked milk flavor, sweet taste, or astringency were noted $(P>0.05)$. These results closely matched findings from Chang and Dando (2018), who reported that sensory changes in skim milk following light exposure were primarily associated with light-exposed flavors (old oil, plastic, cardboard) and not attributes inherent to unexposed skim milk.

The DSI-UP milk was characterized by distinct sulfur or eggy flavors (mean $=1.9$ at $0 \mathrm{~h}$ exposure), which were not present in HTST milk, as well as higher cooked or milk flavors (mean $=3.9$ at $0 \mathrm{~h}$ exposure) compared with HTST milk, consistent with previous studies (Lee et al., 2017; Jo et al., 2018). In addition, unexposed DSI-UP milk was devoid of any light-induced carboard

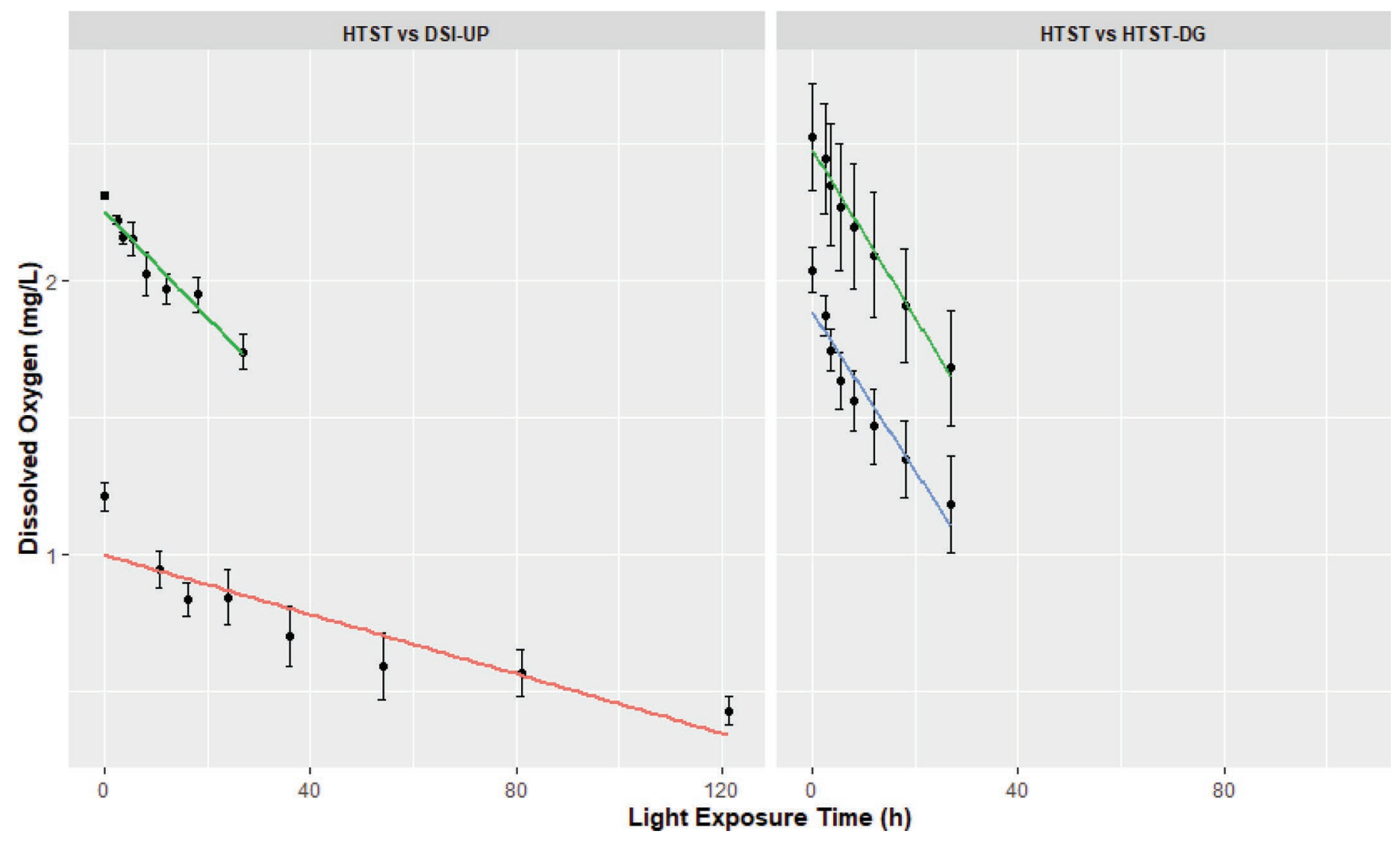

Figure 3. Dissolved oxygen measurements over light exposure time for HTST versus direct steam injection ultrapasteurization (DSI-UP) and HTST versus degassed HTST (HTST-DG) skim milk treatments. Data points represent mean dissolved oxygen measurements, and bars represent the SEM over 3 replicates at each experimental light exposure duration for each treatment. 
or mushroom flavors. The DSI-UP milk was largely similar to HTST milk in terms of flavor profile evolution over light exposure time, although the associated time domains were considerably greater in DSI-UP milk. Trained panelists identified LOF in DSI-UP milk after $36 \mathrm{~h}$ of light exposure, with LOF being characterized by a decrease $(P<0.05)$ in eggy or sulfur flavor (mean $=0.7)$ as well as an increase $(P<0.05)$ in cardboard flavor $($ mean $=0.9)$. Previous studies have indicated that the decrease of eggy or sulfur flavors in UP and UHT milks is associated with the oxidation of sulfhydryl groups on associated compounds, indicating that these flavor compounds may play a direct antioxidant role, thus slowing LOF development (Wadsworth and Bassette, 1985; Adhikari and Singhal, 1992). Mushroom flavor development was not as pronounced in DSI-UP milk compared with HTST, even at extended exposure times, although a higher $(P<0.05)$ signal $($ mean $=1.1$; compared with unexposed control) was noted following $121.5 \mathrm{~h}$ of light exposure. In general, previous sensory analysis studies of LOF in UP and UHT milks are rare, and, to our knowledge, none have described the specific flavor attributes relevant to LOF. However, the identification of LOF development in UP milk following 36 $\mathrm{h}$ of light exposure is roughly in line with triangle test results of untrained panelists reported by Johnson et al. (2015), who noted differences $(P<0.05)$ compared with a light-blocked control between $1 \mathrm{~d}$ and $3 \mathrm{~d}$ of light exposure $(\sim 2,186 \mathrm{~lx})$ in $2 \%$ UP milk.

\section{Volatile Flavor Analysis}

The HTST and DSI-UP milks were distinct in initial volatile compound profile, as expected (Jo et al., 2018). Thermal processing of skim milk via DSI-UP was characterized by higher $(P<0.05)$ relative abundances, compared with HTST, for volatile sulfur compounds such as hydrogen sulfide, carbon disulfide, and dimethyl disulfide (Table 2). These findings were consistent with those reported by Jo et al. (2018), who identified such sulfur compounds as the source of potent sulfur or eggy flavors found in DSI-UP milk. Following $24 \mathrm{~h}$ of light exposure, concentration of hydrogen sulfide decreased $(P<0.05)$ in DSI-UP milk, compared with $0 \mathrm{~h}$ of light exposure measurements, before exhibiting an increasing trend thereafter. Similarly, dimethyl disulfide concentration was lower $(P<0.05)$ at $54 \mathrm{~h}$ of light exposure, compared with $0 \mathrm{~h}$ exposure, before increasing again. These trends suggest that sulfur compounds resulting from DSI-UP thermal processing likely imparted a protective antioxidant effect. Although the antioxidant effects of such compounds have been addressed in previous fluid milk studies, those same compounds have been identified as secondary products of light-induced reactions and components of general LOF in other studies (Jung et al., 1998; Mestdagh et al., 2005). Due to their dichotomous role in the light oxidation process, changes in the concentration of such compounds may be a measurable indication of light-induced oxidation and terminal development of LOF in fluid milk and present an ample area for future study.

The antioxidant effect of sulfur compounds inherent to UP or UHT milk thermal processing is a function of increased free sulfhydryl groups. Sulfhydryl group formation can be primarily linked to $\beta$-lactoglobulin in serum protein, which is unfolded during heating (Liu et al., 2007). In the presence of UV light and singlet oxygen, oxidation reactions readily occur within fluid milk, destroying methionine and unsaturated fatty acids and resulting in the formation of oxidation-related volatiles (Min and Boff, 2002). When present in the fluid milk system, the sulfhydryl groups liberated in high-heat treatments may act as an intermediary, quenching free radicals and slowing the development of oxidation flavors. Solano-Lopez et al. (2005) noted that free sulfhydryl groups in UP milk were particularly reactive reducing agents and provided stability to ascorbic acid-another antioxidant natural found in milk - over the first $30 \mathrm{~d}$ of storage. Similarly, it is likely that the formation of sulfhydryl groups following DSI-UP thermal treatment resulted in decreased oxidation rate in the present study and delayed onset of $\mathrm{LOF}$, as suggested by trained panel findings.

Other sulfur compounds commonly associated with LOF in HTST milk, such as dimethyl sulfide and dimethyl trisulfide, exhibited generally increasing trends. Dimethyl sulfide was higher $(P<0.05)$ in concentration by $36 \mathrm{~h}$ of light exposure, and dimethyl trisulfide was higher $(P<0.05)$ in concentration by $54 \mathrm{~h}$. Clear trends in relative abundances of sulfur compounds were observed; however, many of these changes were nonlinear at extended light exposure times $(54,81$, and 121.5 $\mathrm{h}$ ), further indicating that certain sulfur compounds play a significant role in secondary and tertiary light oxidation reactions (Al-Attabi et al., 2009; Jo et al., 2018).

Aldehydes and ketones commonly associated with oxidized flavor were also investigated (Brothersen et al., 2016; Jo et al., 2018). Initial (unexposed) concentrations of hexanal, heptanal, octanal, and nonanal were not different $(P>0.05)$ in HTST and DSI milks. However, initial concentrations of methional, decanal, benzaldehyde, and 1-octen-3-one were greater in DSIUP milk, consistent with Jo et al. (2018), who identified the presence of sulfur compounds, methyl ketones, and Maillard reaction products as key differentiators between DSI-UP and HTST milk. Over the course of light exposure, both HTST and DSI-UP milks exhib- 
Harwood et al.: LIGHT OXIDATION OF FLUID MILK

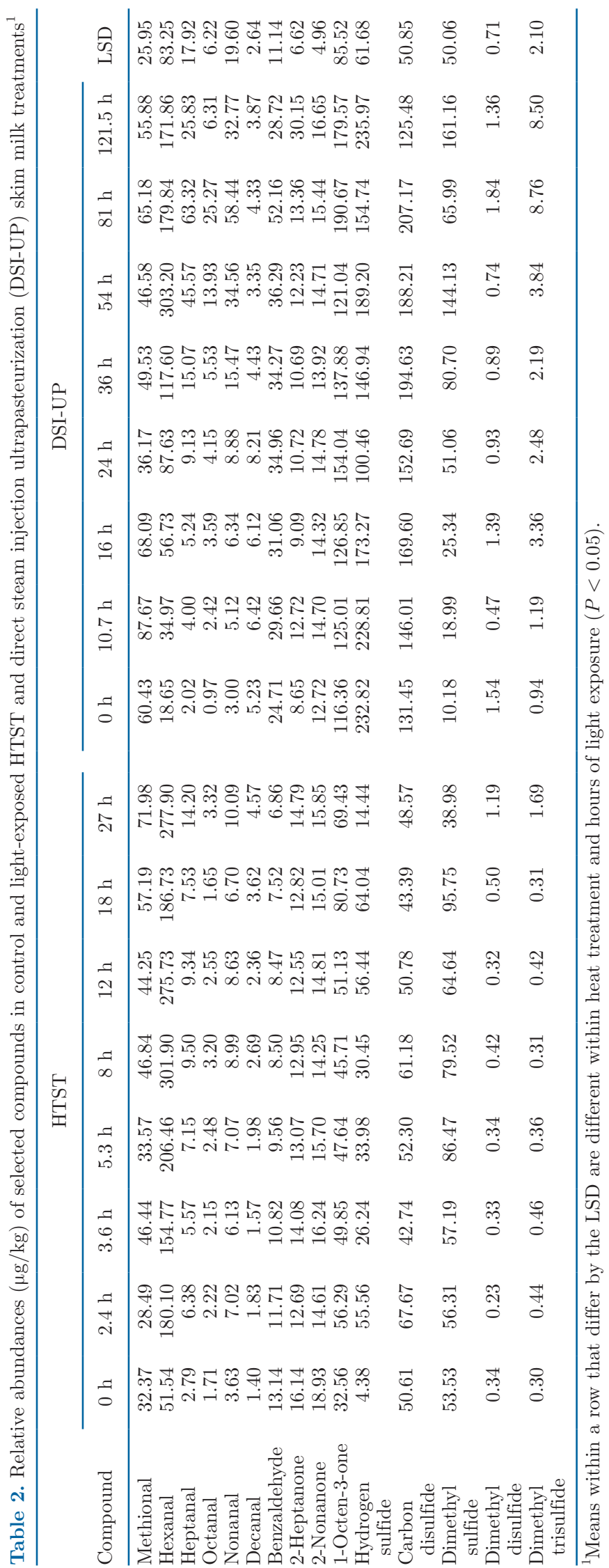


ited increases $(P<0.05)$ in aldehydes and ketones. In HTST milk, formation of cardboard and mushroom flavors determined by the trained sensory panel were correlated $(P<0.05)$ with increases in methional $\left(\mathrm{r}_{\text {cardboard }}\right.$ $\left.=0.77, \mathrm{r}_{\text {mushroom }}=0.78\right)$, hexanal $\left(\mathrm{r}_{\text {cardboard }}=0.82\right.$, $\left.\mathrm{r}_{\text {mushroom }}=0.76\right)$, heptanal $\left(\mathrm{r}_{\text {cardboard }}=0.86, \mathrm{r}_{\text {mushroom }}=\right.$ $0.82)$, nonanal $\left(\mathrm{r}_{\text {cardboard }}=0.82, \mathrm{r}_{\text {mushroom }}=0.77\right)$, and decanal $\left(r_{\text {cardboard }}=0.83, r_{\text {mushroom }}=0.84\right)$. For DSIUP milk, cardboard flavor was significantly correlated $(P<0.05)$ with heptanal $(\mathrm{r}=0.75)$, nonanal $(\mathrm{r}=$ $0.86)$, 2-nonanone $(\mathrm{r}=0.74)$, 2-heptanone $(\mathrm{r}=0.76)$, 1-octen-3-one $(\mathrm{r}=0.81)$, dimethyl sulfide $(\mathrm{r}=0.74)$, and dimethyl trisulfide $(\mathrm{r}=0.92)$, whereas mushroom flavor was significantly correlated $(P<0.05)$ with increased 2-heptanone $(\mathrm{r}=0.92), 2$-nonanone $(\mathrm{r}=0.81)$, 1-octen-3-one $(\mathrm{r}=0.81)$, and dimethyl trisulfide $(\mathrm{r}=$ 0.88 ) concentrations. These findings are consistent with Whitson et al. (2010), who reported that cardboard flavor of whey protein was associated with pentanal, heptanal, and nonanal in the presence of 1-octen-3-one and dimethyl trisulfide. Furthermore, identification of 1-octen-3-one as a primary source for mushroom flavor in UP milk is corroborated by gas chromatography-olfactometry findings reported by Jo et al. (2018). As 1-octen-3-one is formed by the thermal degradation of linoleic acid (Lin and Blank, 2003), it is unsurprising that this characteristically mushroom-like volatile compound is present at initial higher abundance in DSI-UP milk compared with HTST and may play a more direct role in LOF in UP milk.

\section{Threshold Determination}

Estimation of the BET for retronasal detection of LOF in both HTST and DSI-UP skim milk was de- termined following data collection with untrained selfreported skim milk consumers (Figure 4). For HTST skim milk, the population BET was $15.2 \mathrm{~h}$ ( $\mathrm{SD}=2.3$ h), whereas the BET for DSI-UP milk was higher $(P$ $<0.05)$ at $61.0 \mathrm{~h}(\mathrm{SD}=2.0 \mathrm{~h})$. For the HTST treatment, results generally agreed with Chang and Dando (2018), who reported an LOF development threshold of approximately $9 \mathrm{~h}$ in HTST skim milk under light-emitting diode light when assessed by untrained consumers. However, light exposure times associated with the determined BET values from this study are greater than the estimated 2-h BET for LOF in HTST reduced-fat milk exposed to $2,000 \mathrm{~lx}( \pm 5 \%)$ reported by Chapman et al. (2002). Similarly, Walsh et al. (2015) reported that HTST 2\% fat milks exposed to 375-lx fluorescent light for $8 \mathrm{~h}$ received significantly lower liking scores than unexposed controls, suggesting that consumers detected LOF in the light-exposed milks. It should be noted that the present study differed from the aforementioned studies concerning fat content, light type, and threshold determination method; however, the magnitude and direction of observed differences compared with our study with skim milk imply that fat content may play a significant role in flavor degradation from light exposure. Whited et al. (2002) observed that reduced-fat and whole milks exhibited more rapid LOF development compared with skim milk, seemingly contradicting findings within the same study that showed skim milk to be more susceptible to riboflavin and vitamin degradation. Further investigation into the interaction of fat content, light exposure, and other variables is warranted to more thoroughly explore and explain these tendencies in fluid milk.

The greater $(P<0.05)$ BET observed for DSI-UP milk compared with HTST milk, along with consis-

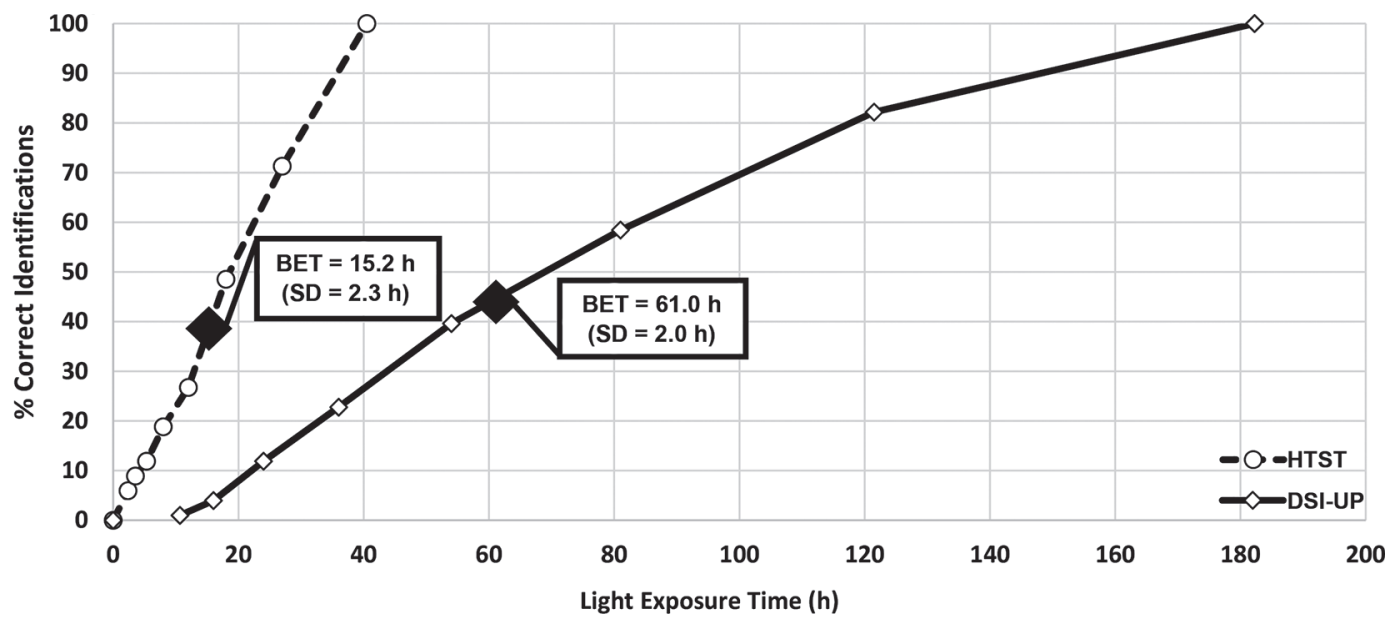

Figure 4. Consumer best estimate threshold (BET) determination from 3 experimental replications $(\mathrm{n}=101$ total evaluations) of lightoxidized flavor for HTST and direct steam injection ultrapasteurization (DSI-UP) skim milks. 
tent trained panel and riboflavin degradation results, demonstrates that thermal processing at the extreme temperature of DSI-UP affects LOF. Sulfur-containing compounds associated with UP treatment of fluid milk have been directly linked to the unique cooked and sulfur or eggy flavors of UP milk (Jo et al., 2019). As these flavors and aromas tended to be more intense than typical light-oxidation flavors (mushroom, cardboard) at early light exposure times, it is likely that the extended threshold for LOF observed for DSI-UP skim milk is a function of masking effects. Sensory masking is a phenomenon where intensity of a sensory signal for a particular component is lessened by the presence of a secondary component. Lawless (2000) noted that sensory masking effects often result in mutual suppression of the components within a system. Within HTST milks, development of LOF seemingly coincided with decreased perception of typical sweet aromatic flavor when evaluated by trained sensory panelists. Similarly, this inverse relationship was mirrored by LOF and eggy or sulfur flavors from DSI-UP processing. Previous studies with ultrapasteurized milk have noted that American milk consumers tend to dislike UP and UHT milks because of the presence of sulfurous flavors and incongruence with HTST milk flavors, with which consumers are more familiar (Chapman and Boor, 2001; Lee et al., 2017). Effects of flavor suppression have been found to be more pronounced when incongruent flavors are present together (Frank et al., 1991). In this way, the presence of eggy or sulfur flavors may be responsible for the delayed onset of LOF detection in DSI-UP milks because they mask typical off-flavors at early stages of light exposure.

\section{Degassing of HTST Milk}

Inclusion of a degassing step resulted in a lower $(P$ $<0.05)$ initial DO concentration for the HTST-DG treatment compared with the HTST control. However, it should be noted that the decrease in DO achieved through the inclusion of a degassing step was not equal $(P<0.05)$ to the level of DO measured in DSI-UP milk. For the DSI-UP treatment, the addition of water and high heat to the system necessitated a greater vacuum $(1,040 \mathrm{~mm} \mathrm{Hg})$ for flash vacuum cooling than was possible or appropriate for the HTST treatment $(380 \mathrm{~mm} \mathrm{Hg})$. A greater vacuum reduces vapor pressure, leading to more efficient removal of dissolved gases within the milk; similarly, higher temperatures reduce oxygen solubility, aiding in the vacuum cooling and degassing process (Carlsson and Jönsson, 2012). The rate of DO decrease in fluid milk is widely considered an indicator of oxidation (Potts et al., 2017). To our knowledge, no previous works have assessed the effect of different DO concentrations in HTST milk. However, previous studies on UHT milk have suggested that milk deaeration had no effect on riboflavin stability during storage (Oamen et al., 1989). Comparison of HTST-DG versus HTST milk was consistent with such findings, as the rate of riboflavin degradation was unchanged when postprocessing DO was decreased (Figure 2). Additionally, rate of DO consumption between HTST and HTST-DG milk treatments was not different $(P>$ $0.05)$. Trained panel sensory evaluations mirrored riboflavin and DO monitoring, as no significant difference $(P>0.05)$ in the formation of LOF was found between HTST and HTST-DG milk treatments. Overall, these findings suggest that the lowering of DO alone does not significantly affect the development of LOF in fluid milk at the levels achievable with HTST processing. However, degassing steps should not be considered unserviceable, as higher initial DO concentrations in UHT fluid milk are associated with greater vitamin losses during extended storage (Oamen et al., 1989).

\section{CONCLUSIONS}

Oxidation following exposure to light has been a long-known source of off-flavor for fluid milk and dairy products. Mitigation of off-flavor development due to light exposure has often been addressed via antioxidant addition or the use of light-shielding materials; however, there has been limited investigation into the role thermal processing plays in the development of LOF in fluid milk. The present study found that DSI-UP milk was associated with a significantly greater $(P<0.05)$ time until the threshold for LOF was reached $(61.0 \mathrm{~h}$ of light exposure) compared with HTST milk (15.2 $\mathrm{h}$ of light exposure). The observed difference in time until LOF onset by consumers was corroborated by a trained sensory panel, who detected LOF in DSI-UP milks after $36 \mathrm{~h}$ of light exposure compared with only $3.5 \mathrm{~h}$ in HTST milk. Evidence suggests that the delayed threshold for DSI-UP milk can be attributed to higher relative abundance of volatile sulfur compounds, which result in sensory masking of early LOF development and possibly impart an antioxidant effect as well. Overall, results from this study demonstrate the advantages of ultrapasteurized milk compared with HTST milks in terms of delayed LOF onset and provide valuable information that may influence future packaging, storage, and retail presentation for such products.

\section{ACKNOWLEDGMENTS}

Funding was provided in part by the National Dairy Council (Rosemont, IL). The use of trade names does not imply endorsement or lack of endorsement of those 
not mentioned. The authors have not stated any conflicts of interest.

\section{REFERENCES}

Adhikari, A. K., and O. P. Singhal. 1992. Effect of dissolved oxygen content on the flavour profile of UHT milk during storage. Aust. J. Dairy Technol. 47:1-6.

Al-Attabi, Z., B. R. D'Arcy, and H. C. Deeth. 2009. Volatile sulphur compounds in UHT milk. Crit. Rev. Food Sci. Nutr. 49:28-47. https://doi.org/10.1080/10408390701764187.

ASTM. 2019. E679-19: Standard Practice for Determination of Odor and Taste Thresholds by a Forced-Choice Ascending Concentration Series Method of Limits. ASTM International, West Conshohocken, PA.

Bills, D. D., C. S. Yang, M. E. Morgan, and F. W. Bodyfelt. 1972. Effect of sucrose on the production of acetaldehyde and acids by yogurt culture bacteria. J. Dairy Sci. 55:1570-1573. https://doi .org/10.3168/jds.S0022-0302(72)85722-9.

Bodyfelt, F. W., J. Tobias, and G. M. Trout. 1988. The Sensory Evaluation of Dairy Products. Van Nostrand Reinhold, New York, NY.

Boor, K. J., and D. N. Nakimbugwe. 1998. Quality and stability of $2 \%$ fat ultrapasteurized fluid milk products. Dairy Food Environ. Sanit. 18:78-82.

Brothersen, C., D. J. McMahon, J. Legako, and S. Martini. 2016. Comparison of milk oxidation by exposure to LED and fluorescent light. J. Dairy Sci. 99:2537-2544. https://doi.org/10.3168/jds.2015 -9849 .

Carlsson, H., and C. Jönsson. 2012. Separation of Air Bubbles from Milk in a Deaeration Process. Lund University Department of Chemical Engineering \& TetraPak Processing Systems AB, Lund, Sweden.

Chang, A. C., and R. Dando. 2018. Exposure to light-emitting diodes may be more damaging to the sensory properties of fat-free milk than exposure to fluorescent light. J. Dairy Sci. 101:154-163. https://doi.org/10.3168/jds.2017-13519.

Chapman, K. W., and K. J. Boor. 2001. Acceptance of $2 \%$ ultrapasteurized milk by consumers, 6 to 11 years old. J. Dairy Sci. 84:951-954. https://doi.org/10.3168/jds.S0022-0302(01)74553-5.

Chapman, K. W., L. C. Rosenberry, D. K. Bandler, and K. J. Boor. 1998. Light-oxidized flavor development and vitamin A degradation in chocolate milk. J. Food Sci. 63:930-934. https://doi.org/10 .1111/j.1365-2621.1998.tb17929.x.

Chapman, K. W., L. J. Whited, and K. J. Boor. 2002. Sensory threshold of light-oxidized flavor defects in milk. J. Food Sci. 67:27702773. https://doi.org/10.1111/j.1365-2621.2002.tb08813.x.

Frank, R. A., G. Shaffer, and D. V. Smith. 1991. Taste-odor similarities predict taste enhancement and suppression in taste-odor mixtures. Chem. Senses 16:183-185.

Gandy, A. L., M. W. Schilling, P. C. Coggins, C. H. White, Y. Yoon, and V. V. Kamadia. 2008. The effect of pasteurization temperature on consumer acceptability, sensory characteristics, volatile compound composition, and shelf-life of fluid milk. J. Dairy Sci. 91:1769-1777. https://doi.org/10.3168/jds.2007-0833.

Jo, Y., D. M. Benoist, D. M. Barbano, and M. A. Drake. 2018. Flavor and flavor chemistry differences among milks processed by hightemperature, short-time pasteurization or ultra-pasteurization. J. Dairy Sci. 101:3812-3828. https://doi.org/10.3168/jds.2017-14071.

Jo, Y., B. G. Carter, D. M. Barbano, and M. A. Drake. 2019. Identification of the source of volatile sulfur compounds produced in milk during thermal processing. J. Dairy Sci. 102:8658-8669. https:// doi.org/10.3168/jds.2019-16607.

Johnson, D. S., S. E. Duncan, L. M. Bianchi, H. H. Chang, W. N. Eigel, and S. F. O'Keefe. 2015. Packaging modifications for protecting flavor of extended-shelf-life milk from light. J. Dairy Sci. 98:2205-2214. https://doi.org/10.3168/jds.2014-8857.

Jung, M. Y., S. H. Yoon, H. O. Lee, and D. B. Min. 1998. Singlet oxygen and ascorbic acid effects on dimethyl disulfide and off-flavor in skim milk exposed to light. J. Food Sci. 63:408-412. https://doi .org/10.1111/j.1365-2621.1998.tb15753.x.
Lawless, H. T. 2000. Sensory combinations in the meal. Pages 92-106 in Dimensions of the Meal-The Science, Culture, Business, and Art of Eating. Aspen Publishers, Gaithersburg, MD.

Lee, A. P., D. M. Barbano, and M. A. Drake. 2017. The influence of ultra-pasteurization by indirect heating versus direct steam injection on skim and $2 \%$ fat milks. J. Dairy Sci. 100:1688-1701. https: //doi.org/10.3168/jds.2016-11899.

Lin, J., and I. Blank. 2003. Odorants generated by thermally induced degradation of phospholipids. J. Agric. Food Chem. 51:4364-4369. https://doi.org/10.1021/jf034300m.

Liu, H. C., W. L. Chen, and S. J. T. Mao. 2007. Antioxidant nature of bovine milk $\beta$-lactoglobulin. J. Dairy Sci. 90:547-555. https://doi .org/10.3168/jds.S0022-0302(07)71538-2.

Marsili, R. T. 1999. Comparison of solid-phase microextraction and dynamic headspace methods for the gas chromatographic-mass spectrometric analysis of light-induced lipid oxidation products in milk. J. Chromatogr. Sci. 37:17-23. https://doi.org/10.1093/ chromsci/37.1.17.

Martin, N., N. Carey, S. Murphy, D. Kent, J. Bang, T. Stubbs, M. Wiedmann, and R. Dando. 2016. Exposure of fluid milk to LED light negatively affects consumer perception and alters underlying sensory properties. J. Dairy Sci. 99:4309-4324. https://doi.org/10 $.3168 /$ jds.2015-9603.

McCarthy, K. S., K. Lopetcharat, and M. A. Drake. 2017. Milk fat threshold determination and the effect of milk fat content on consumer preference for fluid milk. J. Dairy Sci. 100:1702-1711. https: //doi.org/10.3168/jds.2016-11417.

Meilgaard, M., G. V. Civille, and B. T. Carr. 2007. Descriptive analysis techniques. Pages 167-168 in Sensory Evaluation Techniques. 4th ed. CRC Press, Boca Raton, FL.

Mestdagh, F., B. De Meulenaer, J. De Clippeleer, F. Devlieghere, and A. Huyghebaert. 2005. Protective influence of several packaging materials on light oxidation of milk. J. Dairy Sci. 88:499-510. https://doi.org/10.3168/jds.S0022-0302(05)72712-0.

Min, D. B., and J. M. Boff. 2002. Chemistry and reaction of singlet oxygen in foods. Compr. Rev. Food Sci. Food Saf. 1:58-72. https:/ /doi.org/10.1111/j.1541-4337.2002.tb00007.x.

Oamen, E. E., A. P. Hansen, and K. R. Swartzel. 1989. Effect of ultrahigh temperature steam injection processing and aseptic storage on labile water-soluble vitamins in milk. J. Dairy Sci. 72:614-619. https://doi.org/10.3168/jds.S0022-0302(89)79151-7.

Potts, H. L., K. N. Amin, and S. E. Duncan. 2017. Retail lighting and packaging influence consumer acceptance of fluid milk. J. Dairy Sci. 100:146-156. https://doi.org/10.3168/jds.2016-11673.

Rysstad, G., A. Ebbesen, and J. Eggestad. 1998. Sensory and chemical quality of UHT-milk stored in paperboard cartons with different oxygen and light barriers. Food Addit. Contam. 15:112-122. https: //doi.org/10.1080/02652039809374605.

Saidi, B., and J. J. Warthesen. 1995. Effect of heat and homogenization on riboflavin photolysis in milk. Int. Dairy J. 5:635-645. https://doi.org/10.1016/0958-6946(95)00048-8.

Schiano, A. N., Y. Jo, D. M. Barbano, and M. A. Drake. 2019. Does vitamin fortification affect light oxidation in fluid skim milk? J. Dairy Sci. 102:4877-4890. https://doi.org/10.3168/jds.2018-15594.

Silva, L. S. Jr., M. G. Trevisan, S. Rath, R. J. Poppi, and F. G. Reyes. 2005. Chromatographic determination of riboflavin in the presence of tetracyclines in skimmed and full cream milk using fluorescence detection. J. Braz. Chem. Soc. 16:1174-1178. https://doi.org/10 .1590/S0103-50532005000700013.

Solano-Lopez, C. E., T. Ji, and V. B. Alvarez. 2005. Volatile compounds and chemical changes in ultrapasteurized milk packaged in polyethylene terephthalate containers. J. Food Sci. 70:c407-c412. https://doi.org/10.1111/j.1365-2621.2005.tb11438.x.

Stancik, C. M., D. A. Conner, P. Jernakoff, P. M. Niedenzu, S. E. Duncan, L. M. Bianchi, and D. S. Johnson. 2017. Accelerated light protection performance measurement technology validated for dairy milk packaging design. Packag. Technol. Sci. 30:771-780. https:// doi.org/10.1002/pts.2326.

van Aardt, M., S. E. Duncan, D. Bourne, J. E. Marcy, T. E. Long, C. R. Hackney, and C. Heisey. 2001. Flavor threshold for acetaldehyde in milk, chocolate milk, and spring water using solid phase 
microextraction gas chromatography for quantification. J. Agric. Food Chem. 49:1377-1381. https://doi.org/10.1021/jf001069t.

van Aardt, M., S. E. Duncan, J. E. Marcy, T. E. Long, S. F. O'Keefe, and S. R. Nielsen-Sims. 2005. Aroma analysis of light-exposed milk stored with and without natural and synthetic antioxidants. J. Dairy Sci. 88:881-890. https://doi.org/10.3168/jds.S0022 -0302(05)72754-5.

Wadsworth, K. D., and R. Bassette. 1985. Effect of oxygen on development of off-flavors in ultrahigh-temperature milk. J. Food Prot. 48:487-493. https://doi.org/10.4315/0362-028X-48.6.487.

Walsh, A. M., S. E. Duncan, H. L. Potts, and D. L. Gallagher. 2015. Comparing quality and emotional responses as related to acceptability of light-induced oxidation flavor in milk. Food Res. Int. 76:293-300. https://doi.org/10.1016/j.foodres.2015.02.027.

Wang, A., C. H. Dadmun, R. M. Hand, S. F. O'Keefe, J. N. B. Phillips, K. A. Anders, and S. E. Duncan. 2018. Efficacy of light-protective additive packaging in protecting milk freshness in a retail dairy case with LED lighting at different light intensities. Food Res. Int. 114:1-9. https://doi.org/10.1016/j.foodres.2018.07.053.
Webster, J. B., S. E. Duncan, J. E. Marcy, and S. F. O'Keefe. 2009 Controlling light oxidation flavor in milk by blocking riboflavin excitation wavelengths by interference. J. Food Sci. 74:S390-S398. https://doi.org/10.1111/j.1750-3841.2009.01336.x.

Whited, L. J., B. H. Hammond, K. W. Chapman, and K. J. Boor. 2002. Vitamin A degradation and light-oxidized flavor defects in milk. J. Dairy Sci. 85:351-354. https://doi.org/10.3168/jds.S0022 -0302(02)74080-0.

Whitson, M. E., R. E. Miracle, and M. A. Drake. 2010. Sensory characterization of chemical components responsible for cardboard flavor in whey protein. J. Sens. Stud. 25:616-636. https://doi.org/10 .1111/j.1745-459X.2010.00289.x.

Wickham, H. 2016. ggplot2: Elegant Graphics for Data Analysis. Springer, New York, NY.

\section{ORCIDS}

M. A. Drake $\odot$ https://orcid.org/0000-0002-4744-2493 